\title{
Study of obstetric patients admitted to Intensive Care Unit (ICU) at Kathmandu Medical College Teaching Hospital
}

\author{
Saha $\mathbf{R}^{1}$, Shakya $\mathbf{A}^{2}$ \\ 'Dr Rachana Saha, Associate Professor and Head of Department; ${ }^{2} \mathrm{Dr}$ Archana Shakya, Second year resident; \\ Department of Obstetrics and Gynaecology, Kathmandu Medical College Teaching Hospital, Kathmandu, Nepal.
}

\section{Abstract}

Background: Pregnancy though physiological and uneventful can be associated with major maternal morbidity with potential catastrophic consequences requiring utilization of facilities of Intensive Care Unit (ICU). Reports regarding such admissions are few from developing countries.

Objective: To study the indication for admission, intervention and outcome of obstetric patients admitted to intensive care unit at Kathmandu Medical College Teaching Hospital and also to identify risk factors for admission to intensive care unit.

Methods: A hospital based descriptive observational study was conducted from $1^{\text {st }}$ January 2012 to $31^{\text {st }}$ December 2013. All obstetric admissions to the ICU up to 42 days postpartum were included. Data obtained included demography, obstetric history, pre- existing medical problems, indication for ICU admission, intervention in ICU and outcome. Risk factors were assessed by comparing cases with control which included women who delivered before and after the indexed cases.

Results: A total of 50 obstetric patients required ICU admission during the study period. This accounts for $0.87 \%$ of total hospital deliveries and $4.32 \%$ of all ICU admissions. Forty-two percent of the patients were admitted due to hypertensive disorders of pregnancy. Sixteen percent patients were of obstetric haemorrhage. Heart diseases topped the list with $16 \%$ in non-obstetric group. Risk factors for admission included lesser gestational age, Caesareansection, blood loss and co-morbid conditions of the patient. Mean age was $24.5 \pm 4.8$ years; average length of stay in ICU was $3.44 \pm 3.7$ days. Inotropic support was received by six patients (12\%), CVP monitoring was done in three patients $(6 \%)$. Ventilator support was needed in six $(12 \%)$. There were three cases $(6 \%)$ of mortality which accounts for $2.09 \%$ of total ICU mortality. Seventeen patients (34\%) were referred from other centres.

Conclusion: Hypertensive disorders of pregnancy, Obstetric haemorrhage and Heart disease were the most common indications of ICU admissions. Risk factors for admission included lesser gestational age, caesarean section, blood loss, and co- morbid conditions of the patients. Optimal outcome was achieved with combined effort of multidisciplinary team.

Key words: Eclampsia, Intensive care unit, obstetrics, obstetric haemorrhage.

\section{Address for correspondence:}

Dr Rachana Saha

Associate Professor and Head,

Department of Obstetrics and Gynaecology

Kathmandu Medical College Teaching Hospital,

Kathmandu Nepal.

E-mail: rachana_saha@yahoo.com

\section{INTRODUCTION}

The need for critical care support and admission to Intensive Care Unit (ICU) in obstetric patient is relatively infrequent as they are young and healthy group of patients ${ }^{1-7}$. Pregnancy, delivery and puerperium can be complicated by maternal morbidity necessitating intensive care unit admission ${ }^{1-7}$.

Management of such women then becomes multidisciplinary, involving anaesthesiologist, 
obstetricians, nurses and neonatologists ${ }^{1-7}$. Although obstetric patients form a significant proportion of ICU admission in developing countries, there are only few studies reporting on critical illness during preganancy ${ }^{2,4-6}$. Scarpinato et al (as cited in Richa et al) ${ }^{6}$ identified serious lack of knowledge on obstetric care and called for increasing ${ }^{6}$ reporting of data. The aim of this study was to determine the ICU utilization by obstetric patients, to know different reasons for ICU admission, the intervention required and outcome of such admission in ICU in the setting of tertiary care hospital and also to assess risk factors for admission to ICU.

\section{METHODS}

A hospital based descriptive observational study was conducted in the Department of Obstetrics and Gynaecology, Kathmandu Medical College Teaching Hospital (KMCTH) from $1^{\text {st }}$ January 2012 to $31^{\text {st }}$ December 2013. KMCTH is a tertiary care hospital with ICU facilities of 11 beds managed by anaesthesiologists, with broad case mix and caters not only to its own patients but also to referrals from centre to periphery of the country. The unit has facilities for ventilator support, non-invasive cardio-vascular monitoring and is close to dialysis unit. The admission criteria into our ICU to any patient include the need for respiratory support or intensive therapy. The decision for admission is often taken by consultant in the ICU with consultant obstetrician.

All obstetric patients admitted to ICU either from the emergency room, the operating rooms, or from the service ward were enrolled in the study. The patients included all females admitted to the ICU during pregnancy or within
42 days of delivery. Data retrieved included age, parity, co-morbidity, obstetric history, mode of delivery, vital signs. Other data retrieved for each patient pertaining to ICU interventions were mechanical ventilation, use of control or artificial lines, blood products/transfusions, haemodialysis, radiological examination, antihypertensive treatment, inotropic support, and use of magnesium sulphate, length of ICU stay and outcome of such patients. Risk factors were assessed by comparing the cases with controls. Controls included the women who delivered before and after the indexed case. The quantitative variables are presented by their frequency along with percentages. The quantitative variable (scale measurements) is presented by their mean \pm SD values.

\section{RESULTS}

A total of 50 patients were admitted which was $4.32 \%$ of total ICU admissions and $0.87 \%$ of total deliveries. Seventeen $(34 \%)$ patient were referred from outside. Most of cases were post-partum and that too after lower segment Caesarean section (LSCS) i.e. 70\% (Table 2). The mean gestational age varied significantly $(P<0.001)$ for obstetric ICU (cases) and non ICU patients (control) and so was true for amount of blood loss (Table 1).

Eclampsia was the most common (26\%) indication for ICU admission followed by postpartum haemorrhage (14\%) for obstetric cause as shown in Table 3. Similarly for the non-obstetric cause heart disease $(16 \%)$ was most common indication for ICU admission followed by respiratory problems (8\%) as shown in Table 4. Most of the cases $(88 \%)$ were shifted back to the ward and three $(6 \%)$ cases had mortality which was $2.09 \%$ of ICU mortality (Table 6).

Table 1: Characteristics of the ICU Obstetric admission (Mean \pm SD)

\begin{tabular}{lccc}
\hline Characteristics & Cases $(\mathbf{n = 5 0})$ & Control $(\mathbf{n}=\mathbf{1 0 0})$ & P value \\
\hline Age (Years) & $24.5 \pm 4.8$ & $25.9 \pm 5$ & 0.291 \\
\hline Stay in ICU (days) & $3.44 \pm 3.7$ & $3.62 \pm 3.5$ & 0.361 \\
\hline Parity & $1.46 \pm 1.2$ & $1.55 \pm 0.67$ & 0.178 \\
Gestational age (weeks) & $35.28 \pm 4.6$ & $39.04 \pm 1.7$ & $<0.001$ \\
\hline Blood Loss (ml) & $292.24 \pm 225.9$ & $82 \pm 40.3$ & $<0.001$ \\
\hline
\end{tabular}

$p$ value calculated by $t$ test. 
Saha R et al.

Table 2: Mode of delivery among the study participants in two groups.

\begin{tabular}{lcc|}
\hline $\begin{array}{l}\text { Mode of delivery } \\
\text { Cases }(\mathrm{n}=49)\end{array}$ & Control $(\mathrm{n}=100)$ \\
\hline $\begin{array}{l}\text { Lower segment } \\
\text { caesarean section }\end{array}$ & $35(70 \%)$ & $29 \%)$ \\
\hline Normal delivery & $14(28 \%)$ & $71(71 \%)$ \\
\hline
\end{tabular}

$P$ value (calculated by chi-square test) $<0.001$

*one case had ectopic pregnancy

Table 3: Obstetric Indications for ICU Admissions ( $\mathrm{N}=29$ ).

$\begin{array}{lcc}\begin{array}{l}\text { Obstetric Indications } \\ \text { Hypertensive disorder }\end{array} & \text { Number } & \text { Percentage (\%) } \\ \text { of Pregnancy } & & \\ \quad \text { Eclampsia } & 13 & 26 \\ \text { Pre-eclampsia } & 5 & 10 \\ \text { Gestational hypertension } & 2 & 4 \\ \text { HELLP syndrome* } & 1 & 2 \\ \text { Obstetric haemorrhage } & & \\ \quad \text { Post-Partum haemorrhage } & 7 & 14 \\ \text { Ectopic pregnancy } & 1 & 2\end{array}$

*HELLP syndrome: Haemolysis, Elevated liver enzymes and Low platelets

Table 4: Non-Obstetric Indications for ICU admission $(\mathrm{N}=21)$

\begin{tabular}{lcc} 
Non-obstetric indications & Number & Percentage (\%) \\
Heart disease & 8 & 16 \\
Neurological & 2 & 4 \\
Epilepsy & 1 & 2 \\
Meningoencephalitis & \\
\hline Respiratory & 3 & 6 \\
Pulmonary edema & 1 & 2 \\
Suspected pulmonary embolism & 1 \\
$\begin{array}{l}\text { Hepatic disorder } \\
\text { Acute fatty liver of pregnancy }\end{array}$ & 1 & 2 \\
\hline Acute pancreatitis & 1 & 2 \\
\hline Systemic lupus erythematosus 1 & 2 \\
\hline Tocolytic induced tachycardia 1 & 2 \\
\hline Sepsis & 2 & 4 \\
\hline
\end{tabular}

Table 5: Intervention required after ICU admission $(\mathrm{N}=50)$

\begin{tabular}{lcc|}
\hline Interventions & Number & Percentage (\%) \\
\hline Oxygen supplementation & 50 & 100 \\
\hline Blood transfusion & 13 & 26 \\
\hline Inotropic support & 4 & 8 \\
\hline Mechanical ventilation & 6 & 12 \\
\hline Haemodialysis & 2 & 4 \\
\hline Antibiotics & 50 & 100 \\
\hline Magnesium sulphate & 15 & 30 \\
\hline Antiepileptic & 5 & 10 \\
\hline $\begin{array}{l}\text { Central venous pressure } \\
\text { monitoring }\end{array}$ & 6 & 12 \\
\hline
\end{tabular}

Table 6: Outcome of the obstetric patients admitted in ICU $(\mathrm{N}=50)$

\begin{tabular}{lcc}
\hline Outcome & Number & Percentage (\%) \\
\hline Mortality & 3 & 6 \\
\hline Shifted to ward & 44 & 88 \\
\hline Shifted to other ward * & 1 & 2 \\
\hline Left against medical advice. & 2 & 4 \\
\hline * Surgery ward (Co-morbid condition of pancreatitis)
\end{tabular}

\section{DISCUSSION}

Goals in the management of critically ill obstetric patients involve intensive monitoring and physiologic support for patients with life threatening but potentially reversible conditions ${ }^{1,3,6}$. ICU admission is management based criterion and therefore by definition leads to inclusion bias $^{3}$. This is especially the case for tertiary care centres, where the threshold for ICU admission is high due to presence of obstetric high care units ${ }^{3}$.

A total of 50 patients were admitted during the study period with incidence of ICU admission of $0.87 \%$ of all deliveries during the study period and $4.32 \%$ of all ICU admission which was quite low when compared to study done by Upadhyaya et al $^{13}$ in one of the largest maternity hospital of Nepal which showed an ICU admission rate of $2.3 \%$ of all deliveries. Threshold for ICU admission is low in low- volume maternity units due to the fact that local 
protocols require intravenous therapy for pre- eclamspsia to be monitored at an ICU due to logistic reasons ${ }^{3}$.This probably also explains the relatively long duration of ICU stay in low volume and the relatively high share of admission for hypertensive disorder of pregnancy ${ }^{3}$. The $0.87 \%$ admission of all deliveries was quite comparable to the literature reviewed ${ }^{1-16}$ i.e. $<1 \%$ of total deliveries as in developed countries.

The major indications of admission were hypertensive disorder of pregnancy i.e. $42 \%$ followed by obstetric haemorrhage i.e. $16 \%$. All the studies reviewed ${ }^{1-16}$ had similar results. Surprisingly heart disease in pregnancy (16\%) was the top most indication for non-obstetric reasons. May be this is due to the fact that $\mathrm{KMCTH}$ caters to lot of referring patients from various institutes and this patients are referred for combined management.

Majority of the patients were admitted post- partum and that too after caesarean section $(70 \%)$. This again suggests that operative deliveries are associated with high chances of complication which may necessitate ICU admission $^{5}$ or the high relative risk among the women who are delivered by caesarean section is probably as caesarean delivery could be the consequence of underlying diseases for which the mother was admitted rather than risk factor ${ }^{3}$. Risk factors for admission included lesser gestational age, blood loss and associated medical and surgical illness. Selo-Ojeme et al ${ }^{14}$ also in their study found black race, emergency caesarean section and those with primary postpartum haemorrhage as risk factors for admission to ICU. Okafor et $\mathrm{al}^{15}$ in their series found organ dysfunction, massive blood loss, and late presentations as risk factor for mortality. Bouvier Colle et $\mathrm{al}^{16}$ concluded no antenatal consultation, serious past medical history, non-European origin and current multiple pregnancy as risk factors for admission to ICU.

The mean length of stay was $3.44 \pm 3.76$ days which is similar to most studies ${ }^{1-13}$ indicating that most of the patients did not have major complication during their ICU admission. The shortest duration was of 4 hour and maximum duration was of 41 days.

Twelve percent (six) of the patients required mechanical ventilation during their stay in hospital ICU, a rate similar to that reported elsewhere ${ }^{1-13}$. The most common indication for mechanical ventilator was acute respiratory failure and haemodynamic instability. Of the six patients three survived, two left against medical advices in spite of poor prognosis explained and one was given supportive ventilation after caesarean section for eclampsia. Three patients expired. All these patients also required intensive monitoring. Ventilator therapy in developing countries is associated with very high mortality except for mechanical ventilation in the immediate post-operative patients5.

Three $(6 \%)$ mortality were noted among the admitted patients. Two patients expired due to direct obstetric reasons: one from complication of caesarean section leading to broad ligament haematoma formation, atonic post-partum haemorrhage and multi organ failure. The second case was operated case of ectopic pregnancy and which had blood transfusion related acute lung injury with multi organ failure. The third mortality resulted from pulmonary oedema after termination of pregnancy in a case of acute fatty liver of pregnancy.

The marked difference in mortality reported by Baloch et $\mathrm{al}^{4}$ i.e. $68.4 \%$ and this study was due to several reasons. Most of the cases cited in their series were not booked and did not attend prenatal care and delivery was attended by untrained birth attendants but surprisingly in this study two cases had adequate prenatal care. Mortality rate of $41.2 \%$ was reported by Faponle et al ${ }^{5}$. Freda $\mathrm{R}^{6}$ reported $33.3 \%$ of mortality in one university hospital of Lebanon all resulting from medical cause. Upadhya et $\mathrm{al}^{13}$ reported $2.5 \%$ of maternal death resulting from obstetric cause. Though hypertensive disorders of pregnancy was the top most common cause of admission but then there was no mortality and this could be due to use of magnesium sulphate which is the anticonvulsant of choice for treating eclampsia. It reduces cerebral ischemia and results in significant reduction in the need of mechanical ventilation and ICU admission ${ }^{5}$ Optimum care of the circulation and respiration at early stage can clearly minimize the incidence of multi organ failure and late mortality in all critically ill obstetric patients.

\section{CONCLUSION}

This study concludes that $0.87 \%$ of all the deliveries required critical care which is quite comparable to western world. The need of ICU admission has not changed over the past years. Pattern is same all over the world with hypertensive disorders and obstetric haemorrhage being the most common obstetric reasons for admission. Risk 
factors for admission included lesser gestational age, caesarean section, blood loss and co-morbid conditions. The $6 \%$ mortality was within acceptable range with major obstetric haemorrhage topping the list. It also concludes that a close follow up of high risk pregnancy and an optimal stabilization of their condition before intervention improved the outcome of these patients. To reduce the mortality early referral to ICU so as to provide optimum care of circulation, blood pressure and ventilation was necessary so that the prevalence of multi organ failure can be minimized. To achieve all of these a team effort of all disciplines is required.

\section{REFERENCE}

1. Orsini J, Butala A, Diaz L, Muzylo E, Muiuardi C, Kastell P. Clinical Profile of obstetric patients admitted to the Medical Surgical Intensive Care Unit (MSICU) of an Inter-City hospital in NewYork. J Clin Med Res. 2012;4(5):314-317.

2. Aldawodd A. Clinical Characteristics and outcomes of critically ill obstetrics patients: a ten-year review. Ann Saudi Med. 2011 Sep-Oct;31(5):518-22.

3. Lwart JJ, Dupuis JRO, Richters A, Ory F, Roomalen JV. Obstetric intensive Care Unit admission: a 2 Year nationwide population -based Cohort study. Intensive Care Med. 2010 Feb;36(2):256-63.

4. Baloch R, Jakhrani NK, Zeb E, Hafeez S, Abassi M, Abassi FN. Pattern and outcome of obstetric admissions to the surgical intensice care unit- a ten year study. J Surg Pak (International). 2010 Oct-Dec;15(4):171-76.

5. Faponle AF, Adenekan AT. Obstetric admission into the Intensive Care Unit in Suburban University Teaching Hospital. Nep J Obstet Gynaecol. 2011 Nov-Dec;6(2):33-6.

6. Richa F, Karim N, Yazbeck B. Obstretic admissions to the intensive care unit: an eight year review. Lebanese Med J. 2008;56(4):215-19.

7. Pathak V, Agrawal J, Chandra M, Kanash S. Analytical study of patients admitted in obstetric ICU at tertiary care centre. J Evol Med Dental Sci. 2013 Apr;2(14):2246-56.

8. Vasqez DN, Estenssoro E, Canales HS, Reina R, Saenz MG, Das Neves AV, et al. Clinical characteristics and outcomes of obstetric patients requiring ICU admission. Chest. 2007 Mar; 131(3);718-24.

9. Crozier TM, Wallace EM. Obstetric admission to an integrated general intensive care unit in a quaternary maternity facility. Aust $\mathrm{N} \mathrm{Z} \mathrm{J} \mathrm{Obstet}$ Gynaecol. 2011 Jun;51(3):233-8.

10. Lataifeh I, Amarin Z, Zayed F, Mehaisen L, Alchalabi $\mathrm{H}$, Khader $\mathrm{Y}$. Indications and outcome for obstetrics patient's admission to intensive care units: A 7-year review. Informa health care 2010 May;30(4):378-82.

11. Harrison DA, Penmy JA, Yentis SM, Fayek S, Brady AR. Case mix, outcome and activity for obstetric admissions to adult, general critical care units: a secondary analysis of the ICNARC care mix programme Database. Critical care. 2005;9(suppl 3):S25-S37.

12. Madan I, Puri I, Jain NJ, Grotegut C, Nelson D, Dandolu V. Characteristics of obstetric intensive care unit admissions in New Jersey. J Matern Fetal Neonatal Med. 2009 Sep;22(9):785-90.

13. Upadhyaya I, Chaudhary P. Severe Acute Maternal Morbidity and Intensive Care in Paropakar Maternity and Women's Hospital. Nep J Obstet Gynaecol. 2013 Jul-Dec;8(2):38-41.

14. Selo-Ojeme DO, Omosaiye EM, Battacharjee $P$, Kadir ER. Risk factors for obstetric admission to the intensive care unit in a tertiary hospital: a case control study. Arch Gynecol Obstet. 2005;272:20710.

15. Okafor UV, Efetie ER, Amucheazi A. Risk Factors for Maternal Deaths in Unplanned Admissions to the Intensive Care Unit- lessons for Sub- Saharan Africa. Afr J Reprod Health. 2011 Dec;15(4):51-4.

16. Bouvier Colle MH, Varmoux N, Salanave B, Ancel PY, Breast G. Case-control study of risk factors for obstetric patient' admission to intensive care units. Eur J Obstet Gynecol Reprod Biol. 1997 Aug;74(2):173-7. 